\title{
Practical prediction of cyclic humidity effect in creep and shrinkage of concrete
}

\author{
Zdeněk P. Bažant \\ Member, RILEM. \\ Tong-Sheng Wang \\ Visiting Scholar, Northwestern University; on leave from the Huai River Commission, Bangbu, Anhui, China.
}

Professor of Civil Engineering and Director, Center for Concrete and Geomaterials, Northwestern University, Evanston, Illinois 60201; Active

The previously published BP Model for prediction of concrete creep and shrinkage is generalized to cover the increase of creep caused by the cyclic component of environmental relative humidity. A simple formula, which is partly empirical, partly based on the diffusion theory, is proposed and is calibrated by comparisons with test data from the literature.

\section{INTRODUCTION}

Cyclic variations of environmental relative humidity can have an appreciable effect on the long time deformations of concrete structures. Laboratory measurements on test cylinders revealed that the creep of a specimen exposed to cyclic humidity may be as much as twice as large as the creep of a specimen exposed to a constant humidity equal to the average humidity for the other specimen ([1]-[4]).

The $B P$ Model for the practical prediction of creep and shrinkage of concrete, which was originally published in this Journal[5] and later in a simplified form elsewhere [6], and was shown to agree satisfactorily with available test data ([5]-[8]), covers practically all important influences on creep, except for the influence of the cyclic component of environmental humidity. The purpose of this paper is to extend the $B P$ Model to cover this influence, too.

\section{REVIEW OF BP MODEL}

For simplified analysis of structures under service loads, the creep of concrete may be assumed to depend linearly on the stress and its history. The creep properties are then fully defined by the compliance function $J\left(t, t^{\prime}\right)$, also called the creep function, which represents the strain at age $t$ caused by a sustained unit uniaxial stress acting since age $t^{\prime}$ [7]. According to the $B P$ Model [5], equation(25), p. 415 :

$$
\begin{aligned}
& J\left(t, t^{\prime}\right)=\frac{1}{E_{0}}+C_{0}\left(t, t^{\prime}\right)+C_{d}\left(t, t^{\prime}, t_{0}\right) \\
& -C_{p}\left(t, t^{\prime}, t_{0}\right),
\end{aligned}
$$

in which $E_{0}$ is the asymptotic modulus, equal to about 1.5 times the conventional static modulus of elasticity of concrete; $C_{0}\left(t, t^{\prime}\right)$ is the basic creep compliance, i. e. compliance at constant moisture content (as observed on sealed specimens); $C_{d}\left(t, t^{\prime}, t_{0}\right)$ is the additional compliance due to drying at constant environmental relative humidity $h$, with $t_{0}$ being the age of concrete at which the drying exposure begins; and $C_{p}\left(t, t^{\prime}, t_{0}\right)$ is the decrease of creep due to the loss of moisture, as observed on specimens predried to an equilibrium humidity state prior to loading. This last component is usually negligible, except for very thin structural parts after a very long period of drying.

The mathematical description of the basic creep, $C_{0}\left(t, t^{\prime}\right)$, is quite simple, and the double power law is sufficient, although an improvement in the form of the log-double law or the triple power law is possible ([9][11]). The expressions for the creep components due to drying are, however, far more complicated.

The complexity of the formulas for $C_{d}\left(t, t^{\prime}, t_{0}\right)$ has been criticized; however, it is probably inevitable. This is so because, in the simplified prediction which is supposed to be usable even without a computer and without finite element analysis of the stress and strain distributions within cross sections, one needs to describe with $J\left(t, t^{\prime}\right)$ the apparent average creep properties of the entire cross section, rather than the actual creep properties of the material (point properties of the homogenized continuum). The average properties depend on strain-softening and microcracking produced by drying [7]. Moreover, the shrinkage and the creep at drying are not linearly additive components, as assumed for the sake of simplicity in all practical methods of structural creep analysis, but are nonlinearly coupled. These facts became apparent from recent researches at Northwestern University and EPFL Lausanne. If the creep and shrinkage law (as a point constitutive property of a homogenized continuum) is formulated in accordance with the aforementioned facts, its form becomes far simpler than the $B P$ Model, with much fewer parameters. However, the price to pay is that the cross section of a beam can no longer be treated as one unit and a nonlinear problem 


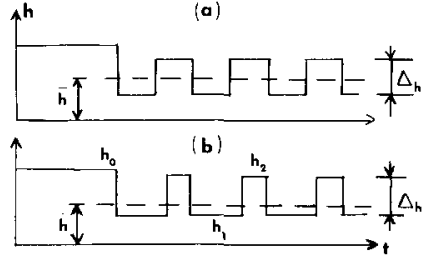

(f)
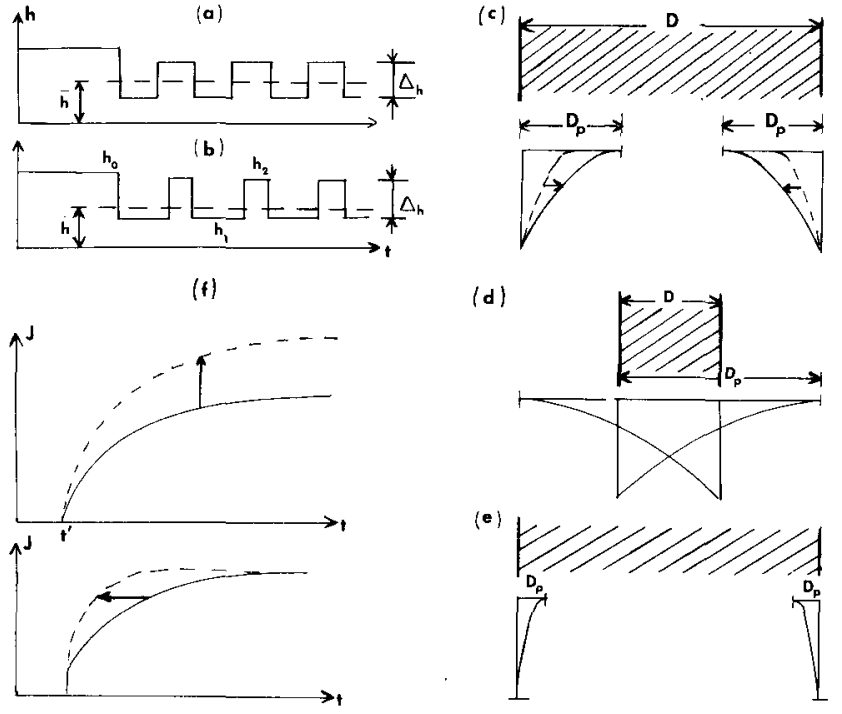

(d)

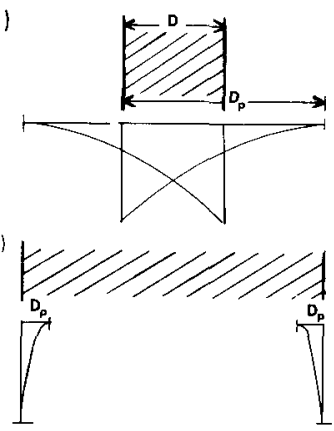

Fig. 1. - Cyclic humidity and illustrations of diffusion effects.

needs to be solved in order to determine the timeindependent multiaxial stress and strain distributions within the cross sections, which may be done by finite elements. This is more realistic than the use of $B P$ Model, but also much more laborious. A practicable prediction model permitting linear creep analysis of structures is needed, even in this computer era, and so we will content ourselves with refining equation(1), while being aware that this is not a fundamental approach to the problem.

The expression for the drying creep term is of the form [6], equations (26)-(29), p. 415 :

$C_{d}\left(t, t^{\prime}, t_{0}\right)=k_{h}^{\prime} \frac{\varphi_{d}^{\prime}}{E_{0}} t^{\prime-m / 2} \varepsilon_{\mathrm{sh}_{\infty}} S_{d}\left(t, t^{\prime}\right)$,

where $\varphi_{d}^{\prime}$ is a function of the delay $t^{\prime}-t_{0}$ of loading after the start of drying [6], equation(26), p. $415, m$ is a constant, $\varepsilon_{\text {sh }_{\infty}}$ is the final shrinkage strain, and:

$S_{d}\left(t, t^{\prime}\right)=\left(1+\frac{10 \tau_{\mathrm{sh}}}{t-t^{\prime}}\right)^{-c_{d} n}$,

$k_{h}^{\prime}=\left|h_{0}^{1.5}-h^{1.5}\right|$.

Here $h$ is the time average relative humidity of the environment, $h_{0}$ is the relative humidity at which the concrete was initially in hygral equilibrium, (usually $h_{0}=0.98$ to 1.00 ), and $\tau_{\text {sh }}$ is the shrinkage square halftime, a constant defining the time when the square of shrinkage reaches one-half of its final value [6], equation(4), p. 308 . According to diffusion theory (linear as well as nonlinear), this parameter may be expressed as:

$\tau_{\mathrm{sh}}=\frac{k_{1}}{C_{1}} D^{2}, \quad D=2 \frac{v}{\mathrm{~s}}$,

in which $D$ is the effective thickness of the cross section, $v / s$ is the volume to surface ratio, $C_{1}$ is the drying diffusivity of concrete at the start of drying, and $k_{1}$ is a certain coefficient depending on the cross section shape [6], equation (4), p. 308.

\section{CONSEQUENCES OF DIFFUSION THEORY}

The formulas of the $B P$ Model are not entirely empirical. In fact their basic form is supported by physical arguments. Aside from those based on the activation energy concept for the effects of temperature on the creep rate and the rate of aging, the $B P$ formulas for drying creep and shrinkage are based on the basic laws of diffusion. The shrinkage and drying creep strains in the interior of a specimen cannot respond instantaneously to a change of environmental humidity. The true, unrestrained shrinkage and creep strain at a point can depend only on the pore relative humidity at that same point, and the effect of environmental humidity can only come due to the diffusion of moisture between that point and the specimen's surface. According to the diffusion theory, $\tau_{\text {sh }}$ should vary as the thickness square and be proportional to the drying diffusivity of moisture. These simple consequences of the diffusion theory indeed yield the best fits of the existing test data, which in turn confirms that the use of diffusion theory is correct.

Diffusion phenomena can have no effect on the terms $C_{0}\left(t, t^{\prime}\right)$ and $C_{p}\left(t, t^{\prime}, t_{0}\right)$ since these correspond to a state of hygral equilibrium. Therefore, similarly to the effect of constant environmental humidity, the cyclic humidity component can affect only the term $C_{0}\left(t, t^{\prime}, t_{0}\right)$. So equation (1) must be generalized as:

$$
\begin{aligned}
& J\left(t, t^{\prime}\right)=\frac{1}{E_{0}}+C_{0}\left(t, t^{\prime}\right) \\
& \quad+\kappa C_{d}\left(t, t^{\prime}, t_{0}\right)-C_{p}\left(t, t^{\prime}, t_{0}\right)
\end{aligned}
$$

in which $\kappa$ is some correction factor for the cyclic humidity component. Functions $C_{d}\left(t, t^{\prime}, t_{0}\right)$ and $C_{p}\left(t, t^{\prime}, t_{0}\right)$ are determined from the same formulas as before, using however the time-average environmental humidity for $h$.

Consider now the history of environmental humidity $h_{e}$ with sudden humidity changes, as shown in figure $1 a$. After each sudden change of $h_{e}$, the points of humidity change propagate from the surfaces of the wall inward. The corresponding humidity profile is shown in figure $1 c$, and the degree of adjustment to the new environmental humidity is given by the ratio of the cross-hatched area in figure 1 to the area $011^{\prime} 0^{\prime}$.

If the period $T$ of the humidity cycle is long or if the wall thickness $D$ is small, then the humidity state of the wall adjusts to the new environmental humidity to a large degree (see fig. $1 d$ ), and if $T$ is short or if the wall thickness is large, then it adjusts to a small degree (see $\mathrm{fig} .1 \mathrm{c}$ ). In the former case the effect of the cyclic humidity component should be about the maximum possible, whereas in the latter case, this effect should be negligible. These facts may be captured by considering coefficient $\kappa$ to be a function of the depth 
of penetration $D_{p}$ of the drying front during one-half of the period $T$.

According to linear diffusion theory:

$D_{p} \simeq \sqrt{6 C_{1} T}$

in which $C_{1}$ is again the drying diffusivity of concrete at the start of exposure to the environment. In absence of information on $C_{1}$, from drying or shrinkage tests, one may use $C_{1} \simeq 0.1 \mathrm{~cm}^{2} /$ day. Equation (7) is true even if the diffusivity of concrete depends on pore humidity, which it does, but its dependence on the age of concrete must be neglected for this equation to hold. This is probably acceptable since the aging rate (hydration rate) in concrete of pore humidity below about 0.95 is negligible.

Now, for $D_{p} \gg D / 2$, the maximum possible effect of humidity cycling is reached, and there should be no dependence of $\kappa$ on thickness $D$. On the other hand, for $D_{p} \ll D / 2$, the effect of the cyclic humidity should be negligible, because only a negligibly thin surface layer of the wall can be affected by the humidity changes. The foregoing two limiting conditions can be most simply described by the function:

$\kappa=1+\kappa_{1}\left(\Delta_{h}\right) \frac{D_{p}}{D_{p}+0.5 D}$,

in which $\kappa_{1}\left(\Delta_{h}\right)$ is a certain empirical function of the amplitude $\Delta_{h}$ of environmental humidity $h$, such that $\kappa_{1}\left(\Delta_{h}\right)=0$ for $\Delta_{h} \rightarrow 0 ; \kappa_{1}$ must not depend on $D$ but might depend also on some other factors. For $D_{p} \gg D / 2$, equation (8) becomes $\kappa \simeq 1+\kappa_{1}=$ const., while for $D_{p} \ll D / 2$, equation (8) becomes $\kappa \simeq 1+2 \kappa_{1} D_{p} / D$, and for $D \rightarrow \infty$ or $D_{p} \rightarrow 0, \lim \kappa=1$. This means that for sufficiently thick cross sections, or for sufficiently short cycles, or for a vanishing relative humidity amplitude, the cyclic humidity component can have no effect.

Coefficient $\kappa$ represents an increase of creep due to humidity cycling ( fig. $1 \mathrm{f}$ ). One might expect that the humidity cycling would also influence the overall rate of time variation of the drying creep term, i. e., would accelerate the drying creep (see fig. $1 \mathrm{~g}$ ). This effect could be taken into account by replacing $\tau_{\text {sh }}$ in equation (3) with $\kappa_{2} \tau_{s h}$ where $\kappa_{2}$ would be some coefficient depending again on $D_{p}$ in the manner of equation (8). This has been tried in fitting the available test data used in the sequel. However, no such effect could be detected in the data. Therefore, it seems possible to neglect acceleration of creep due to humidity cycling $\left(\kappa_{2}=1\right)$.

If the humidity cycles are not of a rectangular shape, or if they are not symmetric, the effect of the humidity cycles on creep should be different. Probably, however, it would not be much different. Anyhow, because test data are lacking we cannot investigate this influence.

\section{EMPIRICAL RELATIONS AND CALIBRATION BY TEST DATA}

From analysis of the test data available in the literature ([1]-[4]), it appeared that coefficient $\kappa_{1}$ should be considered as a function of the duration of loading, $t-t^{\prime}$, and of the humidity period, $T$. The following empirical expression was found to be acceptable:

$\kappa_{1}=2.5 \Delta_{h}\left(1-\mathrm{e}^{-\left(t-t^{\prime}\right) / 10}\right)\left(1-\mathrm{e}^{-T / 5}\right)$,

in which $t, t^{\prime}$ and $T$ must be given in days. The dependence on the load duration is transitional, influencing only the beginning of the response. For load durations $t-t^{\prime} \gg 10$ days, we have $\kappa_{1} \simeq 2.5 \Delta_{h}\left(1-\mathrm{e}^{-T / 5}\right)$. If the cycling period is also long, such that $T \gg 5, \kappa_{1}$ becomes a constant.

In contrast to equations (7)-(8), the dependence of $\kappa_{1}$ on $T$ does not follow from the diffusion theory. In fact, such a dependence must have a different physical source. As a possible explanation, the creep strain, etc. does not respond to a change in pore humidity (at the same location) immediately, but with a certain delay. If so, humidity cycles with a period shorter than this delay can have no effect. A possible cause for such a delay may be a pore structure in which the pore relative humidity governed by the diffusion theory pertains only to large, capillary pores (micropores), while the creep rate is affected only by the state of water in small, subcapillary pores (micropores or gel pores) which communicate with the adjacent macropores with a certain delay.

Only relatively limited test data on the cyclic humidity effect in creep exist in the literature ([1]-[4], [12][14]). Moreover, none of the existing test data present conclusive evidence because the experimental information is incomplete. Ideally, one would need a large set of results from different types of creep tests, such that all the parameters of the $B P$-formulas for creep and shrinkage could be determined by these tests. Since this has not been the case, it is inevitable to predict the missing material parameters using the prediction formulas of the $B P$ Model, which involves a certain uncertainty, and then to adjust only several main parameters so that a good fit of the test data for creep at noncyclic humidity be achieved prior to analyzing the corresponding data for cyclic humidity. All this may be easily accomplished with the computer program MATPAR for the $B P$ Model published in reference [1]. For each data set, the material parameters obtained in this manner are listed in the figures ( figs. 2-5).

The material parameters that had to be adjusted to get optimum fits of the creep data for cyclic humidity were those with the values $2.5,10$ and 5 in equation(9). Since there are only three unknown parameters to be found, a simple trial-and-error procedure is possible. A small computer program was written to fit the data in figures 2-5. Using the material parameters for creep at non-cyclic humidity and chosen values of the three material parameters for creep at cyclic humidity, the program calculates the response curves and automatically plots them. At the same time, it evaluates and prints the sum of squared deviations from the handsmoothed data curves at specified sampling points (same as equation(10) given later). One needs then to make many computer runs for various values of the 

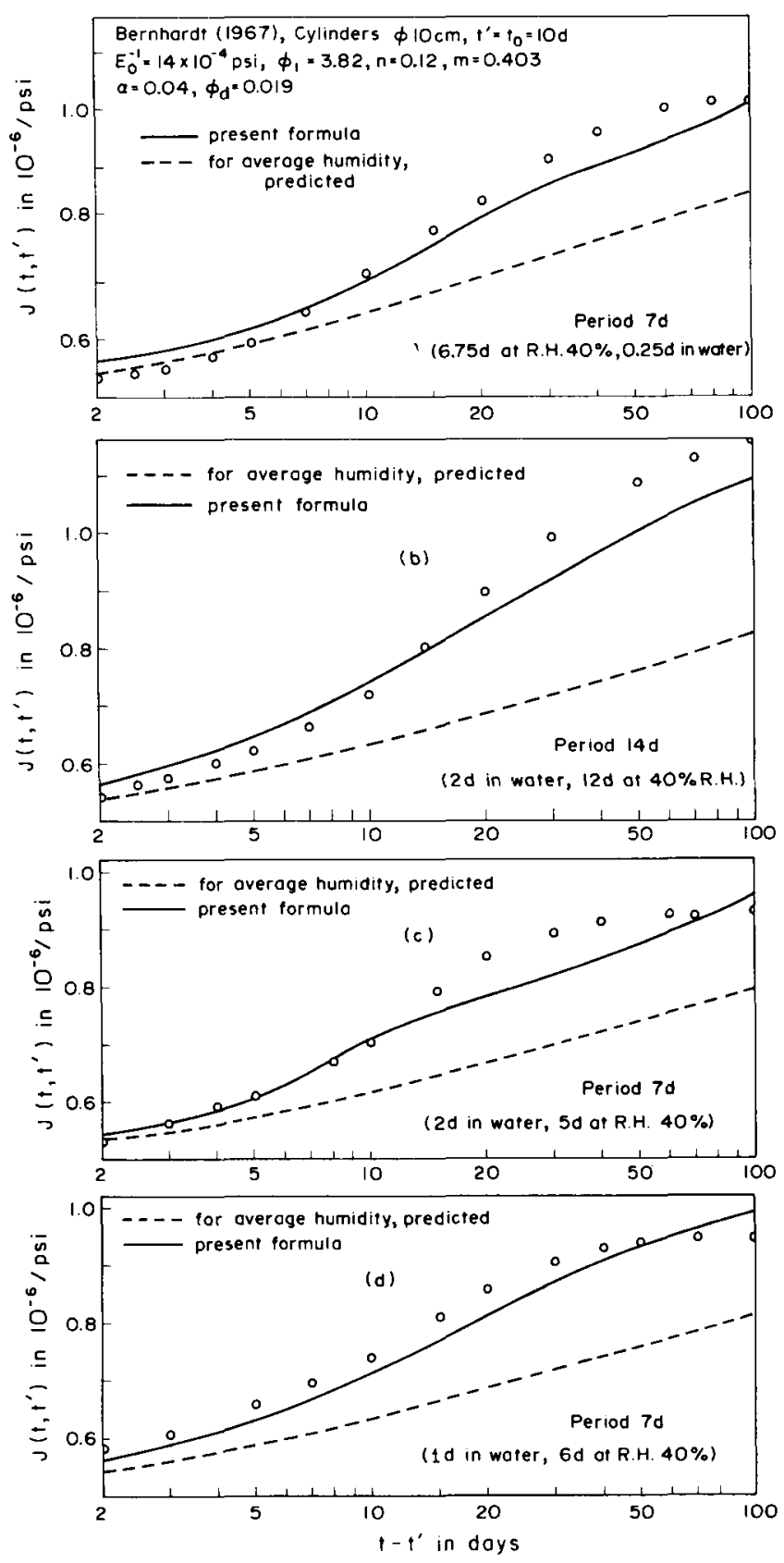

Fig. 2. - Comparison of present formula for creep with Bernhardt's tests (1967).

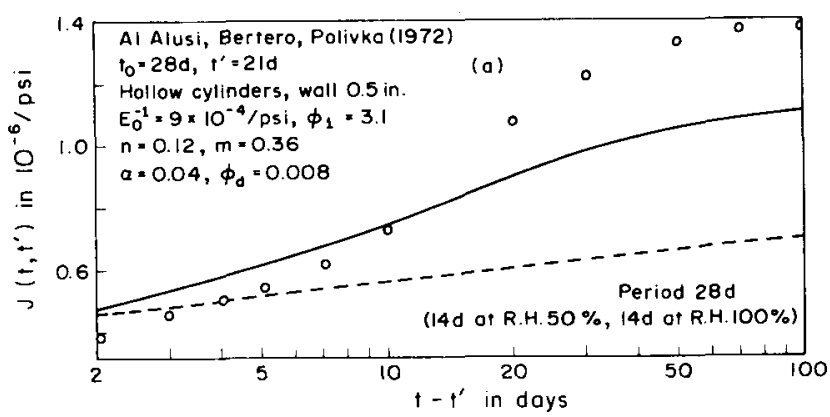

Fig. 3. - Comparison of present formula for creep with tests of AlAlusi et al. (1972) and of Hansen (1960).
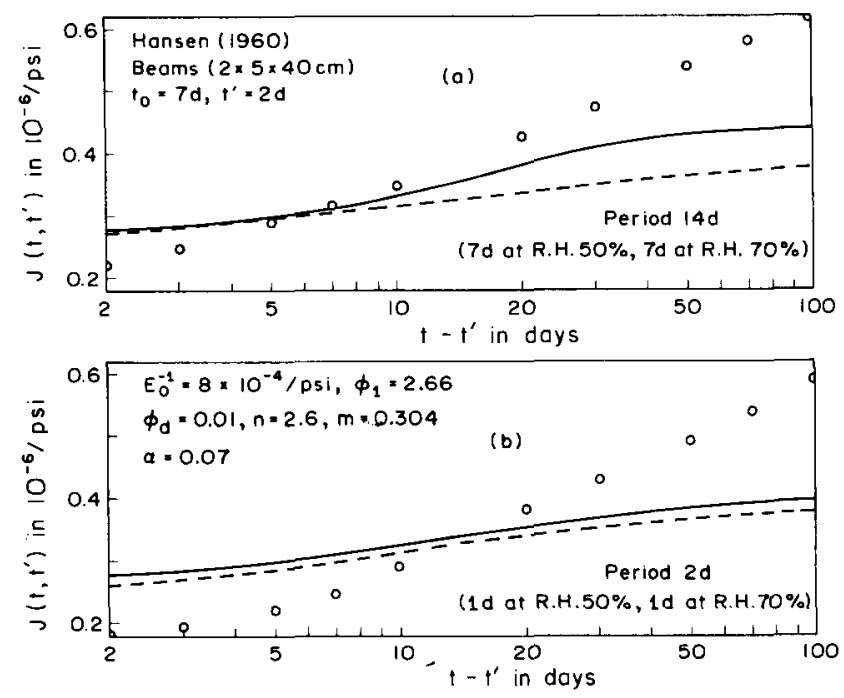

Fig. 4. - Deformations of load-free specimens at cyclic humidity measured by Al-Alusi et al. (1972) and Hansen (1960).

three unknown parameters, in order to identify the parameter values which give overall the best fit, for all available data sets from different laboratories. It should be emphasized that all the three material parameters for creep at cyclic humidity are independent of the type of concrete, and are therefore the same for all data sets.

The present model was calibrated using the data from the creep and shrinkage tests at cyclic humidity by Hansen [4], Al-Alusi, Bertero and Polivka [3] and Bernhardt ([1], [2]). The last data are the most comprehensive ones, and their close fitting has been assigned priority. Figures 2-5 show the comparisons of the present theory (solid lines) with all these data. Other uniaxial compression data exist, too [13], [14], but they were not usable due to insufficient information on the concrete used and its creep properties at non-cyclic humidity.

Statistical information on the data fits is summarized in table I, which lists the coefficients of variation $\omega$ for the deviations from the test data, both for the present model and for the original $B P$ Model with no provision for the cyclic humidity effect. It is seen that a significant reduction in the $\omega$-values is achieved. The unbiased estimates of $\omega$ were calculated as:

TABLE I

COEFFICIENTS OF VARIATIONS $(\%)$ FOR DEVIATIONS OF FORMULAS FROM TEST DATA.

\begin{tabular}{|c|c|c|}
\hline Test Data & Proposed formula & Original formula \\
\hline 1. C. J. Bernhardt $[1] \ldots \ldots$ & 9.1 & 28.1 \\
\hline 2. C. J. Bernhardt $[2] \ldots \ldots$ & 6.5 & 17.4 \\
\hline 3. C. J. Bernhardt [3] & 5.2 & 17.6 \\
\hline 4. C. J. Bernhardt [4] & 5.9 & 17.2 \\
\hline 5. H. R. Al-Alusi et al. & 21.8 & 53.0 \\
\hline 6. T. C. Hansen [1]. . & 24.1 & 34.3 \\
\hline 7. T. C. Hansen [2]. & 31.8 & 34.4 \\
\hline Overall $\bar{\omega}=\left(\sum_{i} \omega_{i}^{2} / 7\right)^{1 / 2}$ & 17.9 & 31.3 \\
\hline
\end{tabular}


$\omega=\frac{s}{\bar{J}}, \quad s=\left(\frac{1}{n-1} \sum_{i=1}^{n} \Delta_{i}^{2}\right)^{1 / 2}$,

$\bar{J}=\frac{1}{n} \sum_{i=1}^{n} J_{i}$.

Here the subscripts $i=1,2, \ldots, n$ denote the sampling points of the data set, which were chosen to be uniformly spaced in the actual time scale; $J_{i}$ are the values of the hand-smoothed data curves at these sampling points (strain caused by load, per unit stress, i. e., the compliance); and $\Delta_{i}$ are the deviations of the calculated values of $J\left(t, t^{\prime}\right)$ from measured $J_{i}$ at these sampling points. Since proportionality to the applied stress is assumed here, all the strain data were converted to compliance data by dividing the strains by the stress.

Bernhardt ([1], [2]) carried out his tests at four different stress levels up to 0.372 of compression strength. The average of the compliances measured for these stress levels was used in the present analysis. Likewise, Al-Alusi et al. [3] used two different types of measurement gages, and the average of the two readings was used here. While Bernhardt and Al-Alusi et al. measured creep under uniaxial compression, Hansen measured bending creep deflections, and to evaluate these data, creep compliance was assumed the same along the beam and on the tensile and compression sides. Nevertheless, the agreement of the present formulas with Hansen's bending test results is worse than with the compression test results. This is not surprising, since bending creep should in theory be described by a different formula. Basic information on the test data used is summarized in Appendix I. It should be noted that there also exist some torsional creep tests at cyclic humidity ([12], [3]), but these would definely require different formulas for their description.
Compression creep is determined as the difference of deformation between a loaded and a load-free specimen subjected to the same environmental history. Therefore, shrinkage at cyclic humidity must also be analyzed. In this regard, the test data by Hansen [4] and Al-Alusi et al. [3] provide some information; see fig. $5(a, b)$. For the former, the environmental humidity fluctuates between 50 and $70 \%$, with $T=28$ days, and for the latter it fluctuates between 50 and $70 \%$, with $T=2$ days and 14 days. From these tests ( fig. 3), it appears that the average of the fluctuating deformation response is about the same as the shrinkage for the time-average constant humidity. Thus, no correction of shrinkage prediction formulas of the $B P$ Model is needed for the case of cyclic humidity.

\section{CONCLUSIONS}

1. The creep prediction formulas of the $B P$ Model can be easily generalized to take approximately into account the increase of creep caused by the cyclic component of environmental humidity.

2. According to diffusion theory, the correction due to cyclic humidity must depend on the cross-section thickness and the humidity period. This dependence may be introduced by means of the well-known expression for the drying penetration depth, and must be such that the correction disappears for a very thick cross section, for a very short fluctuation period and for a very small humidity amplitude.

3. The error of the proposed formula compared to test data from the literature is acceptable in view of the overall scatter of test results.

4. Test data for shrinkage at cyclic humidity do not reveal any systematic difference from shrinkage at average humidity.
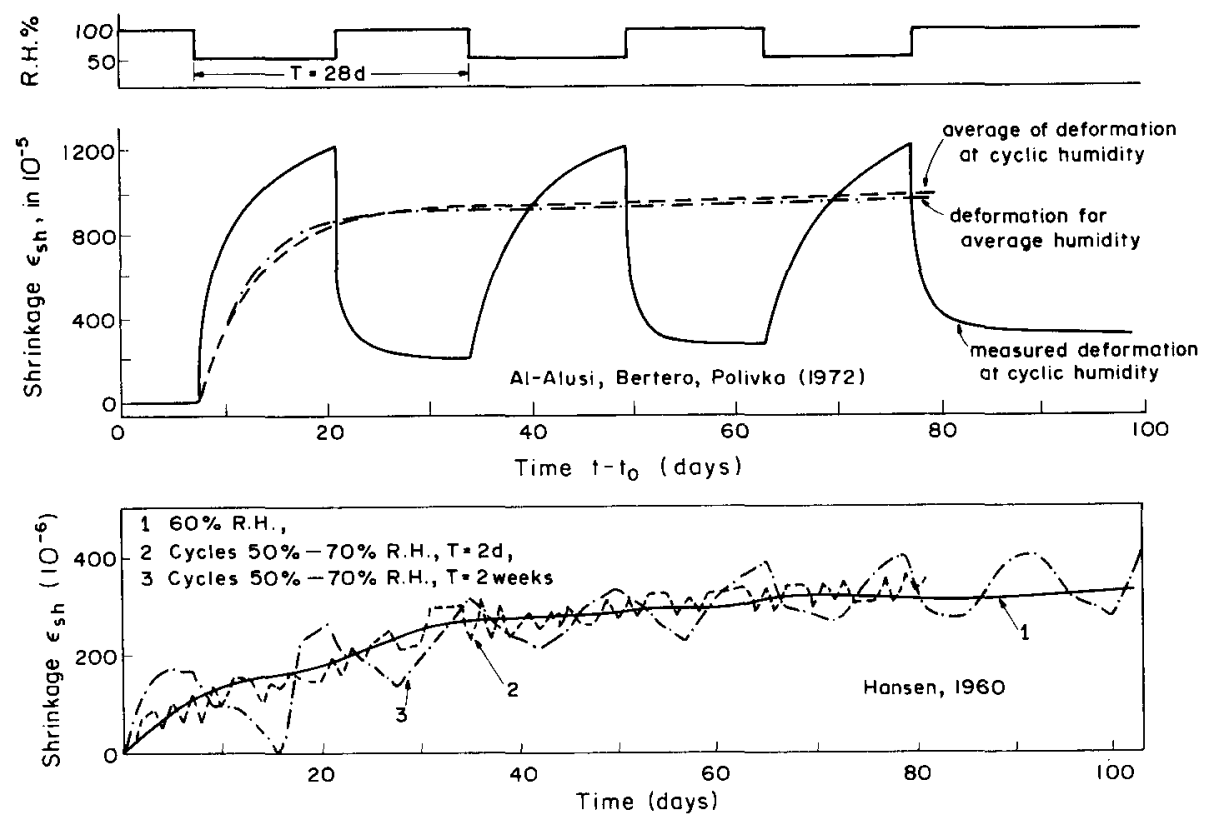

Fig. 5 


\section{ACKNOWLEDGMENT}

Financial support under US National Science Foundation Grant No. CEE 800-3148 to Northwestern University is gratefully acknowledged.

\section{APPENDIX I}

\section{Basic information on test data used}

\section{Bernhardt's tests (1967-1969) ([1], [2])}

Solid cylinders of diameter $10 \mathrm{~cm}$ and length $28 \mathrm{~cm}$, cured at $100 \% \mathrm{RH}$ and $20^{\circ} \mathrm{C}$. The load was applied at age of $9-11$ days. Four test series: I. The period was 14 days, of which 2 days in water and 12 days in air; II-, III-, IV. Period of 7 days for all but different wetting and drying intervals: $2,1,0.25$ day in water, and 5, 6, 6.75 days in air, respectively. The $\mathrm{RH}$ of the air ranged from 35 to $55 \%$. Water, cement, sand, gravel ratio $=0.67: 1: 2.87: 4.3$. 28-days cylinder strength $200 \mathrm{~kg} / \mathrm{cm}^{2}$ (19.62 MPa).

\section{Al-Alusi et al's tests (1972) [3]}

Hollow cylinders of diameters 5 in and 6 in and length 40 in cured at $100 \% \mathrm{RH}, 22.8^{\circ} \mathrm{C}$. Period $T \simeq 28$ days, of which 14 days was wetting at RH $100 \%$, 14 days drying at RH 50\%. Loaded at age 21 days. Water-cement-gravel ratio: $0.58: 1: 2$. Cement content 12 sacks per cubic yard; 21-day cylinder strength 3,600 psi; modulus of elasticity $3.43 \times 10^{6} \mathrm{psi}$.

\section{Hansen's tests (1960) [4]}

Beams $2 \times 5 \times 40 \mathrm{~cm}$. Two test series used here: (1) $T=2$ days (of which 1 day at $\mathrm{RH} 50 \%, 1$ day at R H 70\%). (2) $T=14$ days (of which 7 days at RH $50 \%$, 7 days at $\mathrm{RH} 70 \%$ ). All specimens cured 1 day under wet burlap at $100 \% \mathrm{RH}$, then 6 days in water at $20^{\circ} \mathrm{C}$ and 21 days in air at $70 \% \mathrm{RH}$ and $20^{\circ} \mathrm{C}$. Loaded at age 28 days. Water-cement ratio 0.35 , cement content $850 \mathrm{~kg} / \mathrm{m}^{3}$, volume concentration of cement paste $59 \%$.

\section{REFERENCES}

[1] Bernhardt C. J. - Krypning og Svinn av Betong ved Forskjellige Ytre Forhold. Nordisk Betong, vol. 1, 1967, pp. 9-26.

[2] Bernhardt C. J. - Creep and shrinkage of concrete, Materials and Structures (RILEM, Paris), Vol. 2, No. 8, 1969, pp. $145-148$.

[3] Al-Alusi H. R., Bertero V. V., Polivka M. - Effects of humidity on the time-dependent behavior of concrete under sustained loading, Report No. UC SESM 72-2, Struct. Eng. Lab., Univ. of Calif., Berkeley, Calif., January 1972.

[4] HANSEN T. C. - Creep of concrete. The influence of variations in the humidity of the ambient atmosphere. 6th Congress of the IABSE, Stockholm 1960, Preliminary Publication, pp. 57-65.

[S] BaŽant Z. P., Panula L. - Practical predictions of time-dependent deformations of concrete. Materials and Structures (RILEM, Paris), Vol. 11, No. 65, SeptemberOctober 1978, pp. 307-328: Vol. 11, No. 66, NovemberDecember 1978, pp. 415-434 and Vol. 12, No. 69, MayJune 1979, pp. 169-183.

[6] Bažant Z. P., Panula L. - Creep and shrinkage characterization for analysing prestressed concrete structures. Prestr. Conc. Inst. Journal, Vol. 25, No. 3, 1980, pp. 86122.

[7] BaŽant Z. P., Wittmann F. H. (eds.). - Creep and shrinkage in concrete structures. J. Wiley, London 1982.

[8] BaŽant Z. P., ZeBich S. - Statistical linear regression analysis of prediction models for creep and shrinkage. Cement and Concrete Research, Vol. 13, No. 6, 1983, pp. 869-876.

[9] Bažant Z. P., Chern J. C. - Double power logarithmic law for concrete creep. Cement and Concrete Research. Vol. 14, 1984, pp. 793-806.

[10] Bažant Z. P., Chern J. C. - Log-double power law for concrete creep. Am. Concrete Inst. J. (in press).

[11] Bažant Z. P., Chern J. C. - Triple power law for concrete creep. ASCE J. of Engineering Mechanics, Vol. 111, January 1985, pp. 63-83.

[12] Cucciniello E. - Effects of short-time variation in the environmental conditions upon creep of concrete. Il Cemento, Vol. 70, A pril-June 1973.

[13] Aleksandrovskil S. V. - On hysteresis of shrinkage and swelling at repeated drying and wetting (in Russian). Beton i Zhelezobeton, No. 9, 1958.

[14] AleksandrovskiI S. V. - Analysis of concrete and reinforced concrete structure at temperature and humidity variations with consideration of creep (in Russian). Stroyizdat, Moscow, 1973.

\section{RESUME}

Prévision pratique de l'influence de l'humidité cyclique sur le fluage et le retrait du béton. - Le modèle BP pour la prévision pratique du fluage et du retrait du béton, publié dans ce journal en 1978-1979, est généralisé pour le cas de l'humidité relative de l'environnement qui est cycliquement variable. La composante cyclique de l'humidité cause une augmentation du fluage et du retrait. $D$ 'après la théorie de diffusion, laugmentation du fluage dépend de l'épaisseur de la section du béton ainsi que de la période de variation cyclique de l'humidité. Cette dépendance est exprimée à l'aide de la profondeur théorique de pénétration du front de séchage, et est telle que la correction disparaît pour une épaisseur très grande, pour une période très courte et pour une amplitude d' humidité très petite. En comparaison avec la grande dispersion statistique des mesures, l'erreur de la formule proposée pour l'augmentation de fluage paraît acceptable. En ce qui concerne le retrait, les résultats connus des mesures n'indiquent aucune différence systématique entre le retrait à l'humidité cyclique donnée et le retrait à l'humidité constante égale au moven de cette humidité cyclique. 